\title{
Evaluating the Quality Assurance and Control of Hot- Mix Asphalt from Selected Plants in South West, Nigeria
}

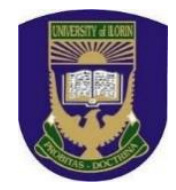

\author{
A. O. Olutaiwo ${ }^{1 *}$, A. Adanikin ${ }^{2}$ \\ ${ }^{1}$ Department of Civil Engineering, University of Lagos, Lagos, Nigeria \\ ${ }^{2}$ Department of Civil Engineering, Elizade University, Ilara-Mokin, Nigeria
}

ABSTRACT: Roads are essential necessity of every nation and it is possible that even with proper designs, the roads might not be constructed to the design standard due to poor quality assurance and control resulting in poor pavement quality. This study presents experimental results carried out on various hot - mix asphalt (HMA) samples obtained across different Asphalt plants in South West Nigeria. This was done to determine the extent to which the HMA used in the construction and rehabilitation of Nigerian roads affect their service life. Six samples of the asphalt binder (bitumen) were obtained from each plant over a period of six months and tested. The tested properties were assessed based on the level of conformance with the specifications and requirements from the FMWH General Specification (Roads and Bridges). The results revealed that HMA from plant B had a specific gravity of 1.01 , penetration of $65.00 \mathrm{~mm}$, softening point of $53{ }^{\circ} \mathrm{C}$, flash point of $237.00{ }^{\circ} \mathrm{C}$, peak Marshall Stability of $18.25 \mathrm{kN}$, flow of $3.87 \mathrm{~mm}$ and voids in total mixture peak value of $5.08 \%$. HMA from plant $\mathrm{E}$ had a specific gravity of 1.03 , penetration of $65.00 \mathrm{~mm}$, softening point of $51{ }^{\circ} \mathrm{C}$, flash point of $239.00^{\circ} \mathrm{C}$, peak marshall stability of $18.26 \mathrm{kN}$, flow of $3.67 \mathrm{~mm}$ and voids in total mixture peak value of 4.99 $\%$ and these were adjudged the best in conformance with the FMWH specifications. Adequate monitoring of HMA quality for either binder or wearing courses by carrying out quality control and assurance tests is thereby recommended as it affects pavement durability and performance.

KEYWORDS: Hot-mix asphalt, quality assurance, quality control, marshall stability, flow test

[Received February 5, 2019, Revised June 21, 2020, Accepted June 25, 2020]

Print ISSN: 0189-9546 | Online ISSN: 2437-2110

\section{INTRODUCTION}

Considering its huge growth and development potential, the performance of Nigerian roads has not been satisfactory (Matawal, 2013). Traditionally, the poor transport facilities and infrastructure have severely delayed economic development and this weakened transport infrastructure has negatively affected attempts to alleviate poverty in the country (Gaal and Afrah, 2017). The Nigerian inland waterways and railways are ineffective, as road transport accounts for $90 \%$ of the internal movement of goods and people and this puts the state of the roads in a grave condition and the more reason they need to receive the much needed rehabilitation interventions (Adanikin and Oyedepo, 2017). The state of Nigerian roads has remained poor for a number of reasons.

The principal reason is poor quality roads were constructed in the first place, due to a combination of faulty designs, lack of drainage, thin wearing course coverings, and negligible quality control of construction materials and execution procedures (Obeta and Njoku, 2016). There appears to be little to no appreciation for maintenance, and when

*Corresponding author: nukee02@gmail.com decisions are made, in most cases they are influenced by politics and not the actual maintenance needs. Zheng et al., (2008) stated that many factors have been identified as the cause of road deterioration but little attention has been paid to the properties of asphaltic concrete used for the construction of the pavement.

Increased use of HMA in pavement construction has many disadvantages, such as environmental degradation, high energy use, increased carbon footprint, low performance for mix processing, low rain and cold weather laying, small construction times each year, oxidative binder hardening, health and safety hazards to workers (Meghna \& Shivananda, 2018). This necessitates the need to ensure quality assurance and control of HMA is undertaken before use. Quality assurance and control entails determining an infrastructures performance to provide confidence that the infrastructure will satisfy relevant quality standards and identifying ways of eliminating unsatisfactory performance (Lakshmi, 2015).

HMA quality assurance and control entails ensuring stakeholders in HMA production comply with minimum material and workmanship requirements to ensure optimal doi: http://dx.doi.org/10.4314/njtd.v17i3.8 
design based performance of the flexible pavements (Sanker et al., 2016). Salvi and Kerkar (2020) in their study revealed that quality assurance (QA) and quality control (QC) help maintain consistency in construction processes to make more cost effective usage of materials leading to substantial cost savings for road users, and this can be achieved pre-construction, during construction and post-construction at different levels of FMA use in pavement construction. Achampong et al., (2013) assert that lack of quality assurance and control is one of the principal reasons that may be causing our perennial road deterioration problems encountered in many developing countries.

Different authors have tried to determine factors that can be used to ensure that HMA satisfies quality assurance and control standards. Akkinepally and Attoh-Okine (2006) recommends increasing the minimum density specification for the various pavement layers to reduce permeability and improve fatigue. Chang et al (2011) recommends use of intelligent compaction technology in Improving quality assurance and control of hot mix asphalt. Chang et al (2011) stated that intelligent compaction technology will result in reduced pavement density variability by improving the consistency of roller patterns during the HMA compaction process by educating the roller operator to use the color coded display on-board. Falade (2013) stated that quality assurance and control of HMA being a road construction material can be achieved by ensuring that relevant quality control tests are carried out on the construction materials, the plants and equipment must be of good quality and must be consistent with the type of job to be done, effective supervision of construction or maintenance works as well as plants and equipment by qualified engineers, contractors complying with all the project specifications.

Akal and El-Matty (2016) using the fuzzy approach reveals that availability of experienced staff in the client and contractor's teams during the project execution, asphalt quality and type used in the construction process, availability of the specified materials quality, pavement not designed according to regional conditions (e.g. soil type -temperature - traffic volume) and design errors arising from poor engineering assumptions and inaccurate data are major causal factors affecting the quality of the highway pavements. Georgiou and Loizos (2019) posit that HMA pavement macrotexture is a key quality attribute to be evaluated in the determination of pavement durability and efficiency, hence the need for quality control methods that are applied in a smart and sustainable manner during pavement construction. Murphy and Murphy (2020) stated that quality aggregates and asphalt make HMA pavements last. Managing input materials in HMA production by monitoring their moisture content, checking the crush, and following the fundamental principles for the sizing, stockpiling, and balancing of recycled inventory helps ensure QA and QC of HMA.

Historically asphalt mix design has been accomplished using either the Marshall or the Hveem design method (Pavement interactive, 2020). In Nigeria, the Marshall Design mix method is adopted and used. In order to preserve the road asset in Nigeria, efforts must be made towards providing pavements that will meet asphaltic concrete design mix specifications under realistic conditions and which will consequently have a reduced life cycle cost. Poor quality control in asphaltic concrete roads construction as indicated by inadequate compaction rates, thicknesses and pavement quality is a major cause of dilapidated roads (Adedimila and Olutaiwo, 2008). Studies on the (QA) and (QC) of Asphalt Cement in Nigeria to assess its role in road pavement deterioration will help in streamlining the list of possible causes and thereby working closer to obtaining the major underlying problem facing our Nigerian roads.

Abubakar (1998) revealed that of all the $32,097 \mathrm{~km}$ of Federal Highways, $18,250 \mathrm{~km}$ are of asphaltic concrete wearing course carriage and another $7,877 \mathrm{~km}$ are made up of asphalt surface dressing, both types being flexible pavements. The remaining $5970 \mathrm{~km}$ are the yet to be constructed earth roads. Still, more than $80 \%$ of the road network is either in fair or poor conditions. From the foregoing, it is seen that more than 90 percent of constructed Nigerian roads are flexible pavement. This implies that Hot-mix Asphalt is a predominant material in pavement construction thereby necessitating studies on quality assurance and quality control measures in HMA production. Therefore, this study aims at contributing to the achievement of long lasting highway pavements in Nigeria by examining the quality assurance and control measures being used by the major players producing hot mix asphalt in the Nigerian construction industry.

\section{STUDY METHODOLOGY}

In studying the Quality Assurance and Quality Control of Hot-mix asphalt (HMA), five (5) Asphalt plants in South West Nigeria were visited and they are used as case study because of their strategic locations, high volume of production and spread. Critical observation of the pre-production process, production and post - production processes for each of the asphalt plants was undertaken. For each batch of asphalt cement produced 6 samples were obtained and checked for consistency.

The Marshall Mix design method was used in this study and it involved aggregate and binder evaluation. The asphalt binder used by each production plant in the production of Hot Mix Asphalt (HMA) were obtained and tested. The asphalt binder samples (bitumen) were obtained directly from the bitumen tanks at various intervals during the research period. Major testing was repeated whenever a new supply of bitumen was delivered to the plant.

The standard requirements from the Federal Ministry of Works and Housing General Specification (Roads and Bridges) Vol. II 1997 - Table VI-15 were used as standards in evaluating the HMA properties. The tests carried out on the bitumen samples include, Specific Gravity Test, Softening Point Test (Ring and Ball Test), Penetration Test and flash Point Test. Laboratory tests were also performed on the HMA to characterize the permanent deformation response of the asphalt pavement materials. These tests include the Marshall Stability, flow test, and voids in total mixture (VTM) test. 


\section{RESULTS AND DISCUSSION}

Results from the preliminary tests on both hot mix asphalt (HMA) samples and Asphalt Binder (Bitumen) are presented and analysed to determine the adherence to the FMWH requirements and specifications.

\section{A. Asphalt Binder (Bitumen)}

Table 1 presents the summary of the preliminary test results carried out on the bitumen samples obtained from all the five (5) plants in question. The asphalt plants have been named Plant A, B, C, D and E.

From Table 1, it was observed that all the bitumen samples (asphalt binder) obtained from each plant, which was used in the manufacture of the Hot mix asphalt (HMA) samples, complied with the Federal Ministry of Works and Housing (FMWH, 1997) Specifications. This could be attributed to the fact that most of the bitumen used across the country for the production of HMA is imported and a high standard of quality control is effected, which produces satisfactory bitumen product.

\section{B. Hot-Mix Asphalt - Extraction Test}

Table 2 presents the summary of the bitumen content test results showing the bitumen content in each sample obtained from each plant under consideration.

From Table 2 and the FMWH specifications, it was observed that all the HMA samples - wearing course obtained from the five (5) plants, comply with the Federal Ministry of Works and Housing (FMWH) Specifications. It is observed that there was a wide variation between successive values in sample C Wearing Samples. This shows the lack of quality control in this aspect except the asphalt plants are producing HMA for just wearing course.

\section{Marshall Stability Test}

According to the FMWH specifications, the Marshall stability value for wearing and binder courses should be greater than 3.5 kN. From Figure 1, reveals that all the HMA samples obtained (wearing and binder course) from each plant comply with the Federal Ministry of Works and Housing (FMWH) Specifications.

\section{Flow Test}

The FMWH specifications for the wearing course HMA flow value include a lower limit of $2 \mathrm{~mm}$ and an upper limit of $4 \mathrm{~mm}$ while the lower and upper limits for binder course are 2 $\mathrm{mm}$ and $6 \mathrm{~mm}$ respectively. Figure 2 shows that all the HMA samples obtained - wearing courses from each plant comply with the FMWH Specifications except sample C1 and C6.

\section{E. Voids in Total Mixture (VTM) Test}

The standard specifications according to FMWH for VTM indicates that the wearing course has an upper limit of 5.0 and lower limit of 3.0. The specification also indicates an upper limit and lower limit of 8.0 and 3.0 respectively for binder course. Figure 3 reveals that samples C1-C6 and samples A2A6 did not comply with the FMWH standard as they exceeded the upper limit for wearing course. Sample D4 also failed the quality control test as its value is below the recommended lower limit for wearing course HMA.

Table 1: Summary of bitumen test results across all five plants.

\begin{tabular}{|c|c|c|c|c|c|c|}
\hline \multirow[t]{2}{*}{ Property } & \multicolumn{5}{|c|}{ Asphalt Plant } & \multirow[t]{2}{*}{ FMWH Specifications } \\
\hline & $\mathbf{A}$ & B & $\mathbf{C}$ & D & $\mathbf{E}$ & \\
\hline Specific Gravity @ 25ㅇ & 1.03 & 1.01 & 1.05 & 1.05 & 1.03 & $1.01-1.06$ \\
\hline 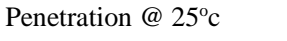 & 63.00 & 65.00 & 64.70 & 66.00 & 65.00 & $60+1-10 \mathrm{~mm}$ \\
\hline Softening Point @ > $5^{\circ} \mathrm{c}$ & 52.00 & 53.00 & 48.60 & 54.00 & 51.00 & $\begin{array}{l}\text { MIN: } 48^{\circ} \mathrm{C} \\
\text { MAX: } 56^{\circ} \mathrm{C}\end{array}$ \\
\hline Flash Point @25c & 233.00 & 237.00 & 235.00 & 242.00 & 239.00 & $\begin{array}{l}\text { MIN: } 225^{\circ} \mathrm{C} \\
\text { MAX: } 250^{\circ} \mathrm{C}\end{array}$ \\
\hline
\end{tabular}

Table 2: Summary of bitumen content results from extraction test on wearing course samples

\begin{tabular}{|c|c|c|c|c|c|c|c|}
\hline \multirow{2}{*}{$\begin{array}{l}\text { Sample } \\
\text { Reference (R) }\end{array}$} & \multicolumn{5}{|c|}{ Bitumen Content (\%) } & \multicolumn{2}{|c|}{ Specifications } \\
\hline & $\mathbf{A}$ & $\mathbf{B}$ & $\mathbf{C}$ & $\mathbf{D}$ & $\mathbf{E}$ & Wearing Course & Binder Course \\
\hline 01 & 4.82 & 5.15 & 7.81 & 5.72 & 5.18 & Lower Limit - 5.0 & Lower Limit - 4.5 \\
\hline 02 & 4.88 & 6.18 & 7.17 & 6.17 & 5.11 & Upper Limit - 8.0 & Upper Limit - 6.5 \\
\hline 03 & 5.89 & 6.11 & 7.66 & 6.00 & 6.13 & - & - \\
\hline 04 & 4.88 & 6.18 & 6.50 & 6.29 & 6.20 & - & - \\
\hline 05 & 5.83 & 5.18 & 7.19 & 6.21 & 6.18 & - & - \\
\hline 06 & 4.99 & 6.09 & 6.00 & 6.27 & 6.08 & - & - \\
\hline
\end{tabular}




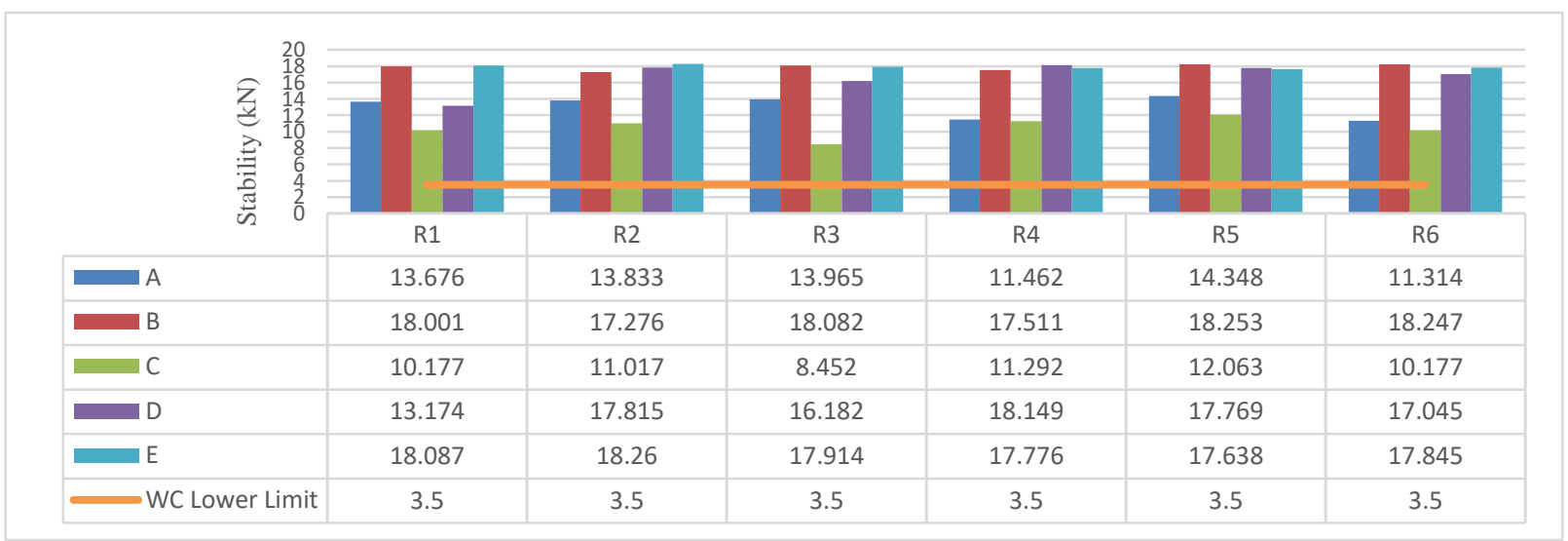

Figure 1: Marshall Stability test result from HMA plants.

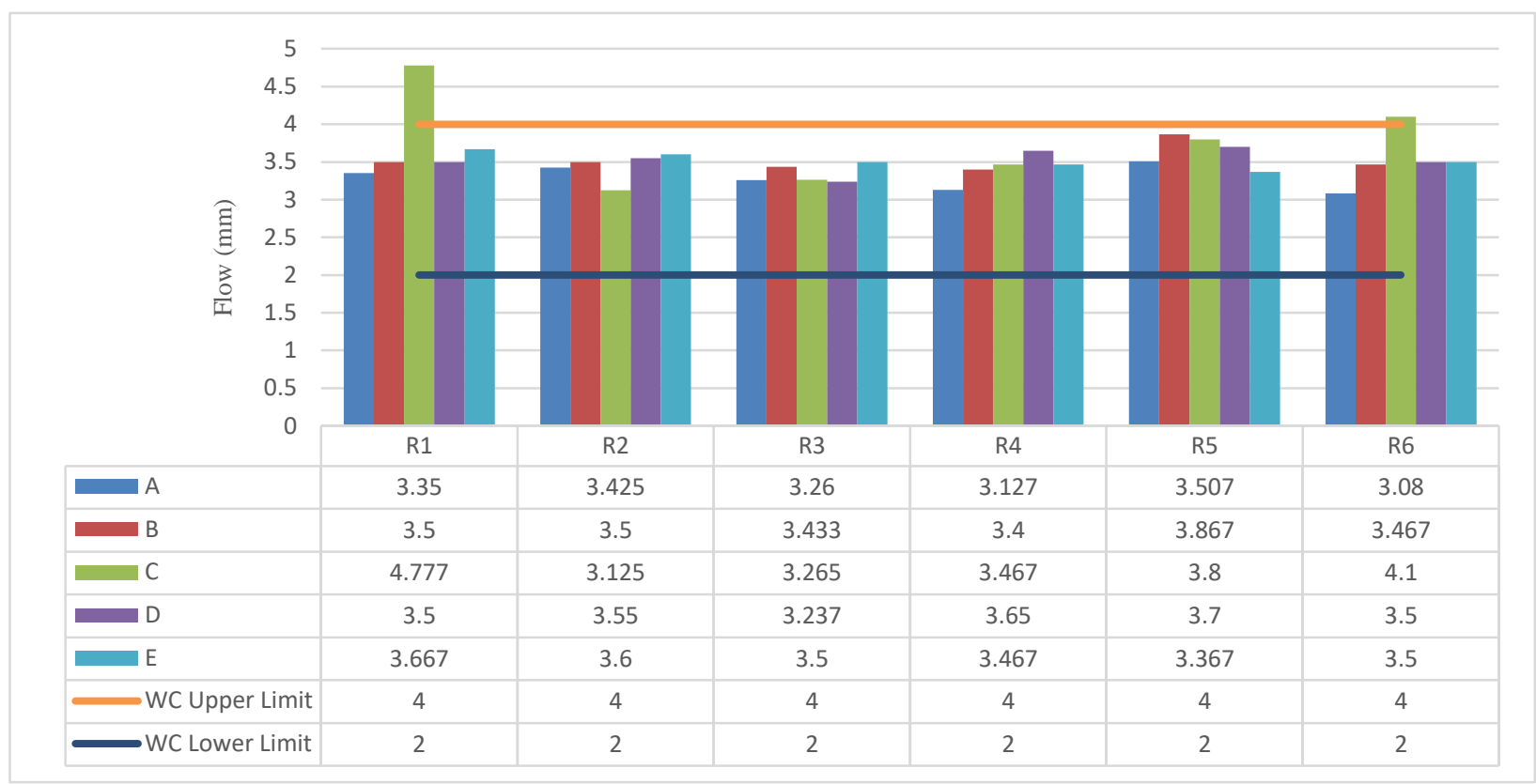

Figure 2: Flow Test Results from HMA Plants.

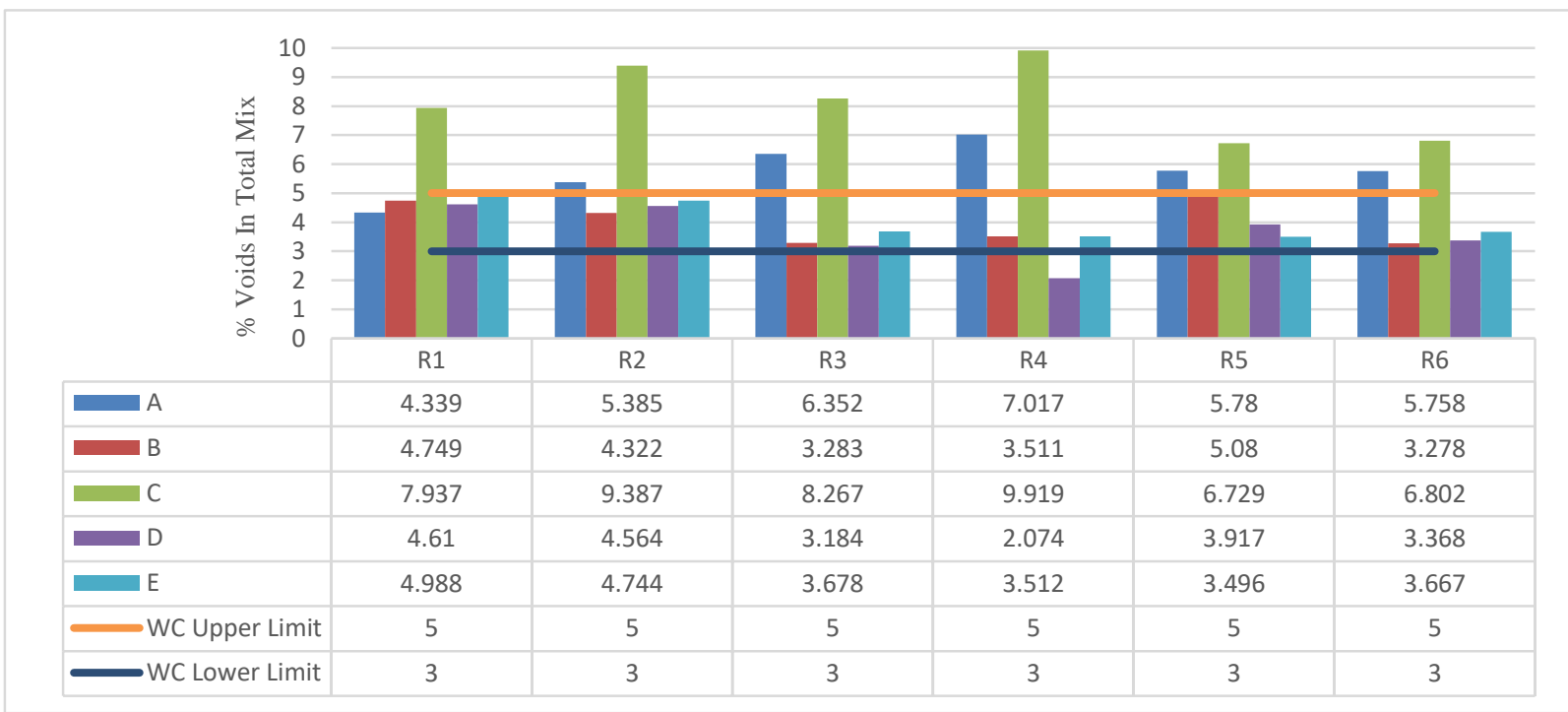

Figure 3: VTM Test Results from HMA Plants. 


\section{CONCLUSION}

In this study, quality assurance and control of Hot-Mix Asphalt (HMA) from selected plants. The study revealed that HMA samples from location B and E were the only samples in full compliance with the requirements of the with the Federal Ministry of Works and Housing (FMWH) Specifications (Roads and Bridges, Vol. II 1997) in terms of the selected parameters for testing. Hot-Mix Asphalt obtained from location $\mathrm{B}$ and $\mathrm{E}$ respectively will be structurally preferable since strength, density and voids, marshall stability and flow and binder content properties are optimum.

It can be inferred that the variation in values between the specified limits for the other plants, shows the gap in the quality assurance and control measures being put in place. For instance, location C HMA samples exhibited very high VTM values over samples from all other plants and the specifications in general while some samples from location D had its VMA values, a little less than the general requirements.

It is concluded that there is a tendency that the perennial road challenges facing the country today, could be as a result of the lack of consistency and poor quality control management entailed in the production of the most common road surfacing material- Hot - Mix Asphalt. However, this is not to say that this is the only factor that has brought the roads in the country to their present condition and level of service.

It is recommended to all highway engineers, contractors, consultants, highway industrialists and any other parties that may be involved in the design, relocation, construction or establishment of road pavement in Nigeria to always ensure adequate monitoring of HMA quality for either binder or wearing courses. This can be achieved by regularly subjecting HMA test samples produced from the plants to standard tests and procedure to check if it is in line with their determined Job-mix formula and the Federal Ministry of Works and Housing (FMWH, 1997) Specifications. The Federal Ministry of Works and Housing (FMWH) is also implored to promote the enforcement of proper checks on the quality of HMA produced prior to laying and promote the education of highway construction practitioners on the longterm effects or consequences of using poorly produced HMA in construction.

\section{REFERENCES}

Abubakar, S. Y. (1998). Investigation of Factors Affecting Rural Road Maintenance - The Case of Sokoto State, Nigeria. PhD Thesis Loughborough University

Achampong, F.; F. Boadu; P. K. Agbeko and R. A. Anum. (2013). Post Construction Failure Analysis of Road Pavements in Ghana. Civil and Environmental Research, 3(7): 74-78.

Adanikin, A. and Oyedepo, O. J. (2017). Public Transport Policy in Developing Countries: Nigeria as a Case Study. $1^{\text {st }}$ International Conference of the School of Management
Technology (SMAT) FUTA, Nigeria, 21-37. Nigeria: SMAT FUTA

Adedimila, A.S. and Olutaiwo, A.O. (2008). Review of Advances in Grading Systems for Asphalt Binders in Hot-Mix Asphalt Pavements. Journal of Engineering and Applied Sciences. 3(4): 322-331

Akal, A. Y. and El-Maaty, A. E. (2016). Fuzzy Assessment of Factors Influencing Quality Level of Highway Projects. International Journal of Management and Fuzzy Systems. 2(2): 6-14

Akkinepally, R. and Attoh-Okine, N. (2006). Quality Control and Quality Assurance of Hot Mix Asphalt Construction in Delaware. Delaware Centre for Transportation University of Delaware. DCT 173.

Chang, G.; C. Xu; R. Horan; L. Michael; D. White and P. Vennapusa. (2011). Final Report: FHWA/Transportation Pooled Fund (TPF) No. 954. Accelerated Implementation of Intelligent Compaction Technology for Embankment Subgrade Soils, Aggregate Base and Asphalt Pavement.

Falade, F. (2013). Quality Control in Road Construction and Maintenance: Practical Approach. Proceedings of National Conference on Road Pavement Failure in Nigeria. 33-55.

FMWH (1997). General Specifications for Roads and Bridges. Federal Ministry of Works and Housing, Nigeria. Vol. II

Gaal, H. O. and Afrah, N. A. (2017). Lack of Infrastructure: The Impact on Economic Development as a Case of Benadir Region and Hir-shabelle, Somalia. Developing Country Studies. 7(1): 49-55.

Georgiou, P., and Loizos, A. (2019). Quality Assurance of HMA Pavement Surface Macrotexture: Empirical Models Vs Experimental Approach. International Journal of Pavement Research and Technology, 12: 356-363.

Lakshmi, S. (2015). Quality Control and Quality Assurance in Building Construction. National Conference on Research Advances in Communication, Computation, Electrical Science and Structures. 29-37

Matawal, D. S. (2013). Road Pavement Failures: Classifications, Causes and Remedies. Proceedings of National Conference on Road Pavement Failure in Nigeria. 115

Murphy, T. R. and Murphy, A. L. (2020). Quality control at your HMA plant. Retrieved from: http://asphaltmagazine.com/quality-control-at-your-hmaplant/

Obeta, I. N. and Njoku, J. E (2016). Durability of Flexible Pavements: A Case Study of South Eastern Nigeria. Nigerian Journal of Technology (NIJOTECH). 35(2): 297 - 305.

Pavement interactive (2020). Hveem Mix Design. Retrieved from: https://pavementinteractive.org/referencedesk/design/mix-design/hveem-mix-design/

Salvi, S. S. and Kerkar, S. S. (2020). Quality Assurance and Quality Control for Project Effectiveness in Construction and Management. International Journal of Engineering Research \& Technology (IJERT). 9(2): 26-29. 
Sanker, P. V.; K. J. B. Chari; R. Tanmai and V. R. Rao. (2016). Investigation on Quality Assurance \& Quality Control in High Rise Buildings. Energy, Environment and Engineering Journal. 7(11): 92-107.

Shivananda, P. (2018). Quality Control of Hot Mix Asphalt Review. International Journal of Applied Engineering
Research. 13(7): 169-173

Zheng, C.; W. Shaopeng; Z. Zu-huang and L. Jiesheng. (2008). Experimental Evaluation on High Temperature Rheological Properties of Various Fiber Modified Asphalt Binders. Journal of Central South University of Technology. 15: 135-139. 